\title{
Removal of persistent organic pollutants from micro-polluted drinking water by triolein embedded absorbent
}

\author{
Huijuan Liu ${ }^{1}$, Jia $\mathrm{Ru}^{2}$, Jiuhui Qu ${ }^{*}$, Ruihua Dai ${ }^{3}$, Zijian Wang ${ }^{4}$, Chun $\mathrm{Hu}^{5}$ \\ State Key Laboratory of Environmental Aquatic Chemistry, Research Center for Eco-Environmental Sciences, Chinese Academy of Sciences, 18, Shuangqing Road, Beijing 100085, China
}

\section{A R T I C L E I N F O}

\section{Article history:}

Received 5 October 2008

Received in revised form 19 January 2009

Accepted 20 January 2009

Available online 25 February 2009

\section{Keywords:}

Persistent organic pollutants

Absorbent

Triolein

Water treatment

\begin{abstract}
A B S T R A C T
A new biomimetic absorbent, cellulose acetate (CA) embedded with triolein (CA-triolein), was prepared and applied for the removal of persistent organic pollutants (POPs) from micro-polluted aqueous solution. The comparison of CA-triolein, CA and granular activated carbon (GAC) for dieldrin removal was investigated. Results showed that CA-triolein absorbent gave a lowest residual concentration after $24 \mathrm{~h}$ although GAC had high removal rate in the first $4 \mathrm{~h}$ adsorption. Then the removal efficiency of mixed POPs (e.g. aldrin, dieldrin, endrin and heptachlor epoxide), absorption isotherm, absorbent regeneration and initial column experiments of CA-triolein were studied in detail. The linear absorption isotherm and the independent absorption in binary isotherm indicated that the selected POPs are mainly absorbed onto CA-triolein absorbent by a partition mechanism. The absorption constant, $K$, was closely related to the hydrophobic property of the compound. Thermodynamic calculations showed that the absorption was spontaneous, with a high affinity and the absorption was an endothermic reaction. Rinsing with hexane the CA-triolein absorbent can be regenerated after absorption of POPs. No significant decrease in the dieldrin removal efficiency was observed even when the absorption-regeneration process was repeated for five times. The results of initial column experiments showed that the CA-triolein absorbent did not reach the breakthrough point at a breakthrough empty-bed volume (BV) of 3200 when the influent concentration was $1-1.5 \mu \mathrm{g} / \mathrm{L}$ and the empty-bed contact time (EBCT) was $20 \mathrm{~min}$.
\end{abstract}

(c) 2009 Elsevier Ltd. All rights reserved.

\section{Introduction}

Persistent organic pollutants (POPs) are characterized by pronounced persistence against chemical/biological degradation, high environmental mobility, strong tendency for bioaccumulation in human and animal tissues and significant impacts on human health and the environment even at extremely low concentrations. POPs have been detected in rivers, soils, the atmosphere and often even in milk or human tissues. In China, POPs could be detected from the surface water, such as the Guanting reservoir, the Yongding river and so on (Kang et al. 2003; Guo et al., 2008). Most POPs are lipophilic chemicals and they are present at low concentrations in water, usually varying between nanogram and picogram per liter and sometimes hundreds of nanograms per liter in micro-polluted surface waters (Zhang et al., 2002; Guo et al., 2008). Their

\footnotetext{
* Corresponding author. Tel.: +86 10 62849151; fax: +86 1062923558.

E-mail addresses: hjliu@rcees.ac.cn (H. Liu), Jiaru@rcees.ac.cn (J. Ru), jhqu@ rcees.ac.cn (J. Qu), dairuihualg@sohu.com (R. Dai), wangzj@rcees.ac.cn (Z. Wang), huchun@rcees.ac.cn (C. Hu).

1 Tel./fax: +86 1062849160 .

2 Tel.: +861062849178.

3 Tel.: +861062849137.

4 Tel.: +861062849140.

5 Tel.: +861062849171.
}

low concentration makes them refractory to the conventional treatment of drinking water.

Adsorption has been widely used as an effective method for removing organic compounds from water. Various adsorbents including activated carbon (Wang and Liu, 2001; Bembnowska et al., 2003; Matsui et al., 2003), natural materials such as sugar cane bagasse, green coconut shells, chitin, and chitosan (Crisafully et al., 2008; Li et al., 2009), organoclays (Lee et al., 2004) and DNA hydrogel beads (Liu et al., 2005) have been reported for POPs removal. However, it is difficult to remove trace level POPs near the environmental levels by these adsorbents.

Even at trace concentrations in water, lipophilic organics can be accumulated by organisms. Many studies have been carried out on bioaccumulation in diverse organisms such as white whales (Andersen et al., 2001), marketable fish (Ahmed and Aly, 2004), white seabream (Ferreira et al., 2008) and mussels (Azza et al., 2004). Semipermeable membrane devices (SPMD), which are based on the diffusion of hydrophobic substances from water to membrane bags filled with lipophilic phases, are widely used for monitoring organic contaminants in water (Huckins et al., 1990; Frank, 2005). It has also been reported that triolein embedded cellulose acetate (CA) membrane could quickly and efficiently accumulate hydrophobic POPs from water (Xu et al., 2005; Ke et al., 2006). In the present study, a novel composite absorbent 
containing the lipid triolein was designed using the concept of bioaccumulation and was used to remove trace level lipophilic organics from water. The absorbent was prepared by embedding triolein into CA spheres. Earlier preliminary study showed that triolein was effectively embedded into CA spheres, and the CA-triolein absorbent was stable in water. This new absorbent are promising for the removal of non-polar compounds.

The purpose of this paper is to study the absorption properties of POPs on CA-triolein absorbent. Aldrin, dieldrin, endrin and heptachlor epoxide, which were detected from the surface water frequently, were selected as the model pollutants. The removal efficiency of four POPs, the absorption isotherm and the reusability of CA-triolein absorbents were studied. Special attention was on the absorption capacity in fixed-bed columns as an indicator of the viability to future implementation of a full-scale process.

\section{Methods}

\subsection{Absorbent preparation}

CA-triolein absorbent was prepared according to the procedures in our previous work (Liu et al., 2007) and was briefly described here. Homogeneous solution of CA (Chemical Reagent Corporation, Shanghai, China) in acetone was prepared and certain amount of triolein (99\% purity, Sigma, USA), water, $\mathrm{Mg}\left(\mathrm{ClO}_{4}\right)_{2}$ and Tween 80 were then added to the solution. The mixtures were stirred at $35 \pm 0.5^{\circ} \mathrm{C}$ for at least two days in order to assure uniform mixing. According to the preliminary experiments, the optimum content of the distilled water in casting solution, which was used as a pore forming agent was about $12-14 \%(w / w)$. Thus, viscous syrups were prepared and homogeneous phases were obtained. Then, the viscous syrup was added dropwise to a glass tube containing the liquid olefin (about 2/3 of the volume). The temperature ranges of the CA solution and liquid olefin were kept at $30-35^{\circ} \mathrm{C}$ and $15-20^{\circ} \mathrm{C}$, respectively. During the dripping process of the viscous syrup through the air to the column of liquid olefin and through the action of surface tension, a white, spherical absorbent was formed which was collected at the bottom of the glass tube. Finally, composite absorbents were washed with distilled water to remove all soluble residues. The TOC of the leachate was determined using a Phoenix 8000 Total Organic Carbon Analyser (Tekmar-Dohrmann Co., USA). After changing the water up to 10 times over a three day period, the TOC level of the leachate was near that of distilled water. CA spheres were also prepared using the above method but without triolein. All of the absorbents were stored in distilled water before use.

\subsection{Absorption experiment}

\subsubsection{Adsorbates}

Four selected POPs, namely, aldrin, dieldrin, endrin and heptachlor epoxide, were used as target pollutants. The physicochemical properties of these four pollutants are presented in Table 1 . These compounds had similar molecular weights but different hydrophobicities, as indicated by their aqueous solubilities and octa- nol-water partitioning coefficients $\left(\log K_{\mathrm{ow}}\right)$. The $\log K_{\mathrm{ow}}$ of aldrin is 5.663, the highest of the four POPs. POPs aqueous solutions were prepared by directly adding the POPs standard solutions to deionized water in sealed conical flasks. The mixtures were then agitated for $8 \mathrm{~h}$ using a horizontal shaker at $170 \mathrm{rpm}$ and $25^{\circ} \mathrm{C}$ to dissolve the organics in water homogeneously.

\subsubsection{Removal test}

Comparing with GAC: The effectiveness of the novel absorbent was compared with GAC using dieldrin as model pollutant. Sorption experiments were carried out in triplicate with three sorbents, e.g. CA, CA-triolein and GAC in batch mode. The initial concentration of dieldrin was $10 \mu \mathrm{g} / \mathrm{L}$. One gram of sorbent was employed in contact with a solution of $200 \mathrm{~mL}$ at $170 \mathrm{rpm}$ at $25^{\circ} \mathrm{C}$. Experiments were continued for $24 \mathrm{~h}$. Samples were withdrawn at regular intervals for analysis.

POPs removal by $C A$ and $C A$-triolein absorbents: POPs removal efficiency by CA and CA-triolein absorbent were examined as follows: One gram of absorbent (CA-triolein and CA) was brought into contact with a solution of $200 \mathrm{~mL}$ which was spiked with mixed POPs standard and each compound concentration was $1 \mu \mathrm{g} / \mathrm{L}$. Samples were withdrawn at regular intervals (e.g., 0.5, 1, 1.5, 2, 4, 6, 8, 12 and $24 \mathrm{~h}$ ) for analyses.

\subsubsection{Absorption equilibrium studies}

A series of $500 \mathrm{~mL}$ conical flasks were filled with $200 \mathrm{~mL}$ distilled water, which was spiked with single or binary POPs (e.g., aldrin, dieldrin, endrin or heptachlor epoxide) and the mixtures were supplied with $1 \mathrm{~g}$ CA-triolein absorbent or $1 \mathrm{~g} \mathrm{CA}$ absorbent. The spiking concentrations of POPs in water ranged from 1 to 20 $\mu \mathrm{g} / \mathrm{L}$. The solutions were sealed in conical flasks and shaken on a horizontal shaker at $170 \mathrm{rpm}$, and the temperature was controlled at $25^{\circ} \mathrm{C}$ or $40^{\circ} \mathrm{C}$ by air bath. Samples for analyses were taken after $72 \mathrm{~h}$ contact time. Preliminary kinetic tests were carried out and equilibrium was assumed when no further changes in POPs uptake were observed after $72 \mathrm{~h}$.

\subsubsection{Reusability of CA-triolein absorbent}

After examining the POPs absorptivity of CA and CA-triolein absorbents, the absorbents were rinsed with distilled water, wiped up with clean filter paper, and dialyzed in $10 \mathrm{~mL}$ of hexane for $48 \mathrm{~h}$. The absorption process was as follows: $1000 \mathrm{~mL}$ of mixed solution of four POPs (the concentration of aldrin was $20 \mu \mathrm{g} / \mathrm{L}$ and the dieldrin, endrin and heptachlor epoxide was $100 \mu \mathrm{g} / \mathrm{L}$ ) contacted with $0.5 \mathrm{~g}$ absorbent for two days by electrical magnetic blender at $25^{\circ} \mathrm{C}$ in sealed conical flasks. Dialysis solutions were evaporated under a gentle stream of nitrogen and analysis by GC. Then, the removal efficiency of the four POPs was examined again following the same procedures as described above. This experiment was repeated five times.

\subsubsection{Column experiments}

Since one of the objectives of the present work was to simulate the POPs removal in a full-scale tower, mini-column experiments

Table 1

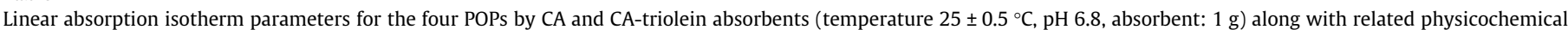
properties.

\begin{tabular}{|c|c|c|c|c|c|c|c|}
\hline Compound & Molecular weight & Water solubility $\left(\mathrm{mg} \mathrm{L}^{-1} @ 25^{\circ} \mathrm{C}\right)$ & $\log K_{\text {ow }}$ & $K_{\text {CA-triolein }}{ }^{\mathrm{a}}$ & $r^{2}$ & $K_{\mathrm{CA}}{ }^{\mathrm{b}}$ & $r^{2}$ \\
\hline Aldrin & 365 & 0.027 & 5.663(BrÁs et al. (1999)) & 21114 & 0.990 & 9199 & 0.991 \\
\hline Deldrin & 381 & 0.195 & 5.48 (Mackay (1982)) & 18681 & 0.991 & 8312 & 0.983 \\
\hline Endrin & 381 & 0.25 & 4.56 (Mackay (1982)), 4.63 (Xu et al. (2005)) & 14269 & 0.987 & 7280 & 0.989 \\
\hline Heptachlor epoxide & 389.2 & 0.35 & $4.51(\mathrm{Xu}$ et al. (2005)) & 13178 & 0.982 & 6624 & 0.988 \\
\hline
\end{tabular}

\footnotetext{
a The slope of linear regression, equilibrium partition coefficient between CA-triolein absorbent and water.
}

b The slope of linear regression, equilibrium partition coefficient between CA absorbent and water. 
were conducted using four selected POPs as model pollutants. The mixed solution (1-1.5 $\mu \mathrm{g} / \mathrm{L}$ of each compound) was conducted by a pump through a tube to CA-triolein and CA absorbent beds, placed in a tube of $2 \mathrm{~cm}$ internal diameter, with fine grids at the top and the bottom to avoid CA-triolein absorbent entrainment. The POPs solution passing through the CA-triolein and CA absorbent bed, and was finally collected for chemical analysis. The size of the absorbent was about $0.5 \mathrm{~mm}$ and the water stream was fixed to a given flow, and a given amount of CA and CA-triolein absorbent (about $12 \mathrm{~g}$ ) was placed in the tube bed in order to simulate a typical absorption tower, with an empty-bed contact time (EBCT) of $20 \mathrm{~min}$. The breakthrough point is considered $0.1 \mu \mathrm{g} / \mathrm{L}$ base on the maximum contaminant level (MCL) of endrin or heptachlor epoxide in drinking water of USEPA (USEPA, 2002).

\subsection{Analysis methods}

The surface areas of CA and CA-triolein absorbents were determined from nitrogen adsorption/desorption isotherms measured at $77 \mathrm{~K}$ by an ASAP 2000 surface analyser (Micromeritics Co., USA).

POPs were present in the water samples at trace levels, so their analysis first required extraction and concentration. SPE (C-18 SPE cartridges, $500 \mathrm{mg}, 3 \mathrm{~mL}$, Agilent Technologies, USA) was used for the extraction of residual concentrations of POPs in samples $(200 \mathrm{~mL})$. A gas chromatograph (HP6890 N) equipped with a ${ }^{63} \mathrm{Ni}$ electron capture detector (GC-ECD) and a HP-5 fused silica capillary column $(30 \mathrm{~m} \times 0.32 \mathrm{~mm} \times 0.25 \mu \mathrm{m})$ was used to determine the residual concentration of the POPs studied. The temperatures of the injector and the detector were kept at $250{ }^{\circ} \mathrm{C}$ and $300^{\circ} \mathrm{C}$, respectively. The column temperature was programmed at $85^{\circ} \mathrm{C}$, increased at $10^{\circ} \mathrm{C} / \mathrm{min}$ to $180^{\circ} \mathrm{C}$, increased at $20^{\circ} \mathrm{C} / \mathrm{min}$ to $280^{\circ} \mathrm{C}$, and then held at $280^{\circ} \mathrm{C}$ for $20 \mathrm{~min}$. Nitrogen of extra purity (>99.999\%) was used as the carrier gas. The flow rate was $2.5 \mathrm{~mL} \mathrm{~min}^{-1}$ and the pressure was kept at 20 psi. Data were collected and analysed with Agilent Chem-Station. The method detection limits (MDLs) of POPs were taken to be 5:1 signal versus noise value $(\mathrm{S} / \mathrm{N})$. The MDLs for aldrin, dieldrin, endrin and heptachlor epoxide was $72.7,82.4,55.1$ and $48.1 \mathrm{pg} / \mathrm{L}$, respectively with the relative standard derivation (RSD\%) values ranging from $4.3 \%$ to $6.6 \%$.

All model calculations and simple linear regressions were performed with the use of Origin for Windows version 7.5 software.

\subsection{Quality control}

Analysis of three blanks ( $200 \mathrm{~mL}$ deionized water) was conducted to assess the interference from the reagents and glassware. Control experiments were conducted using conical flasks containing no absorbent to determine the loss of solutes to assess the interference from the reagents and glassware. The results showed that average system losses were consistently less than $2 \%$ of the initial concentrations of the four POPs. All experiments in this study were conducted in triplicate. GC analysis was repeated twice for each replicate sample. The instruments were calibrated daily with calibration standards. The relative percent difference between the five point calibration and the daily calibrations was $<20 \%$ for all

Table 2

Physical properties of GAC, CA and CA-triolein sorbents.

\begin{tabular}{llll}
\hline Sample & $\begin{array}{l}\text { BET surface area } \\
{\left[\mathrm{m}^{2} / \mathrm{g}\right]}\end{array}$ & $\begin{array}{l}\text { Average pore } \\
\text { diameter }[\mathrm{nm}]\end{array}$ & $\begin{array}{l}\text { Pore volume } \\
{\left[\mathrm{m}^{3} / \mathrm{g}\right]}\end{array}$ \\
\hline GAC & 890 & 1.5 & 0.22 \\
CA absorbent & 27 & 10.9 & 0.07 \\
CA-triolein & 40 & 5.9 & 0.06 \\
\hline
\end{tabular}

target analyses. Recoveries of POPs ranged from $60.3 \%$ to $112.1 \%$, and the relative standard deviations (RSDs) were less than $15 \%$. The study of the recoveries of the targeted analytes demonstrated that moderate recoveries and good repeatability were obtained in the process of the experiment. The blank runs revealed no impurities, and so no interference affected the analytical quality.

\section{Results and discussion}

\subsection{Physical properties of three sorbents}

Three sorbents, CA, CA-triolein, and GAC, were used for removal of dieldrin from water. The prepared CA and CA-triolein absorbent was a white, spherical granule with the size of about $0.5 \mathrm{~mm}$. The GAC selected in this study was produced in Shanxi province and had a particle size of $10-20$ mesh. We selected this GAC because it was widely used in the water treatment plants in China and offered a high purity level. The physical properties of three sorbents were showed in Table 2. The BET surface of GAC, CA and CA-triolein absorbent (14\% triolein loaded) was 890,27 and $40 \mathrm{~m}^{2} \mathrm{~g}^{-1}$, respectively. The average pore diameter of the CA and CA-triolein was 10.9 and $5.9 \mathrm{~nm}$, respectively, and which higher than that of GAC $(1.5 \mathrm{~nm})$. The pore volume $\left(0.22 \mathrm{~m}^{3} / \mathrm{g}\right)$ of GAC was higher than that of CA or CA-triolein.

\subsection{Removal efficiency of dieldrin by three sorbents}

Fig. 1 shows the residual concentration of dieldrin by CA-triolein, CA and GAC as a function of time. The absorption was rapid in the first $4 \mathrm{~h}$ for all three sorbents with GAC showed the faster uptake rate comparing with the other two sorbents. The residual concentrations were $0.94,1.39$ and $1.65 \mu \mathrm{g} / \mathrm{L}$ for GAC, CA-triolein and CA, respectively after $4 \mathrm{~h}$. And then, there was a gradual decrease in the removal rate as the experiment proceeded. After absorption for $24 \mathrm{~h}$, the residual concentration of dieldrin in the adsorption systems of GAC, CA-triolein and CA were 0.39, 0.09 and $0.45 \mu \mathrm{g} / \mathrm{L}$, respectively. It can be seen that CA-triolein absorbent gave the lowest residual concentration. Since the BET surface area of CA-triolein was much lower than that of GAC, the higher absorption efficiency of CA-triolein should relate to the accumulation of lipophilic organics in triolein phase. Xu et al. (2005) also showed that strongly hydrophobic compounds having high values of $\log K_{\mathrm{ow}}$ had a greater tendency to accumulate in the triolein phase. So we want to try this absorbent in the POPs removal micro-polluted water.

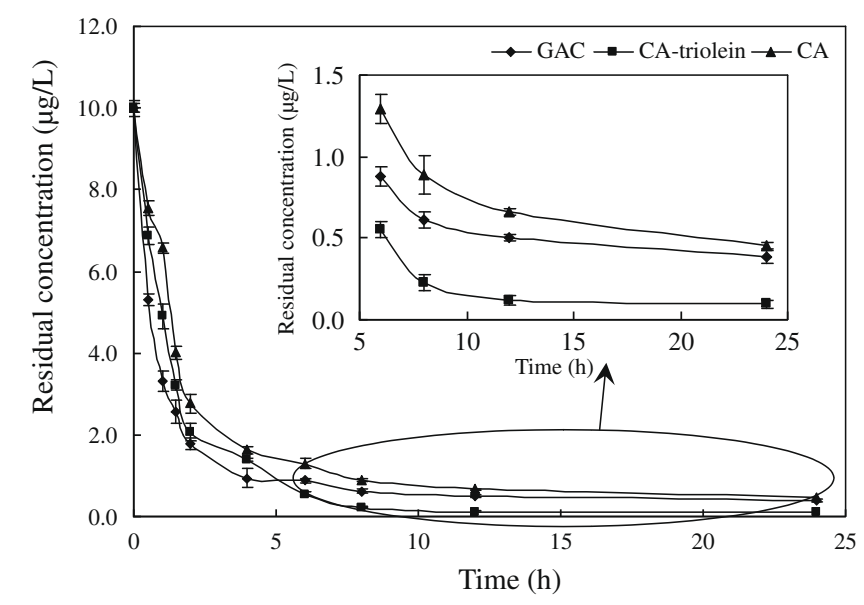

Fig. 1. Residual concentration of dieldrin as a function of time using GAC, CAtriolein and CA beads as sorbents (initial concentration: $10 \mu \mathrm{g} / \mathrm{L}$, liquid: $200 \mathrm{~mL}$, sorbent: $1 \mathrm{~g}$, sorption time: $24 \mathrm{~h}$. Error bars represent standard deviation). 


\subsection{Removal efficiency of mixed POPs by CA and CA-triolein absorbent}

Fig. 2 shows the removal efficiency of the four selected POPs at each initial concentrations of $1 \mu \mathrm{g} / \mathrm{L}$ using CA-triolein absorbent (Fig. 2a) and CA absorbents (Fig. 2b) at different time intervals. As seen in Fig. 2a, the absorption of POPs onto the CA-triolein absorbent was found to be time-dependent. The adsorption was rapid in the first $6 \mathrm{~h}$ until the residual concentrations reached 0.06 , $0.12,0.18$ and $0.20 \mu \mathrm{g} / \mathrm{L}$ for aldrin, dieldrin, endrin and heptachlor epoxide, respectively. And then, there was a gradual decrease in the removal rate as the experiment proceeded. After absorption for $24 \mathrm{~h}$, the residual concentrations of aldrin, dieldrin, endrin and heptachlor epoxide, were no detection, 0.01, 0.02 and
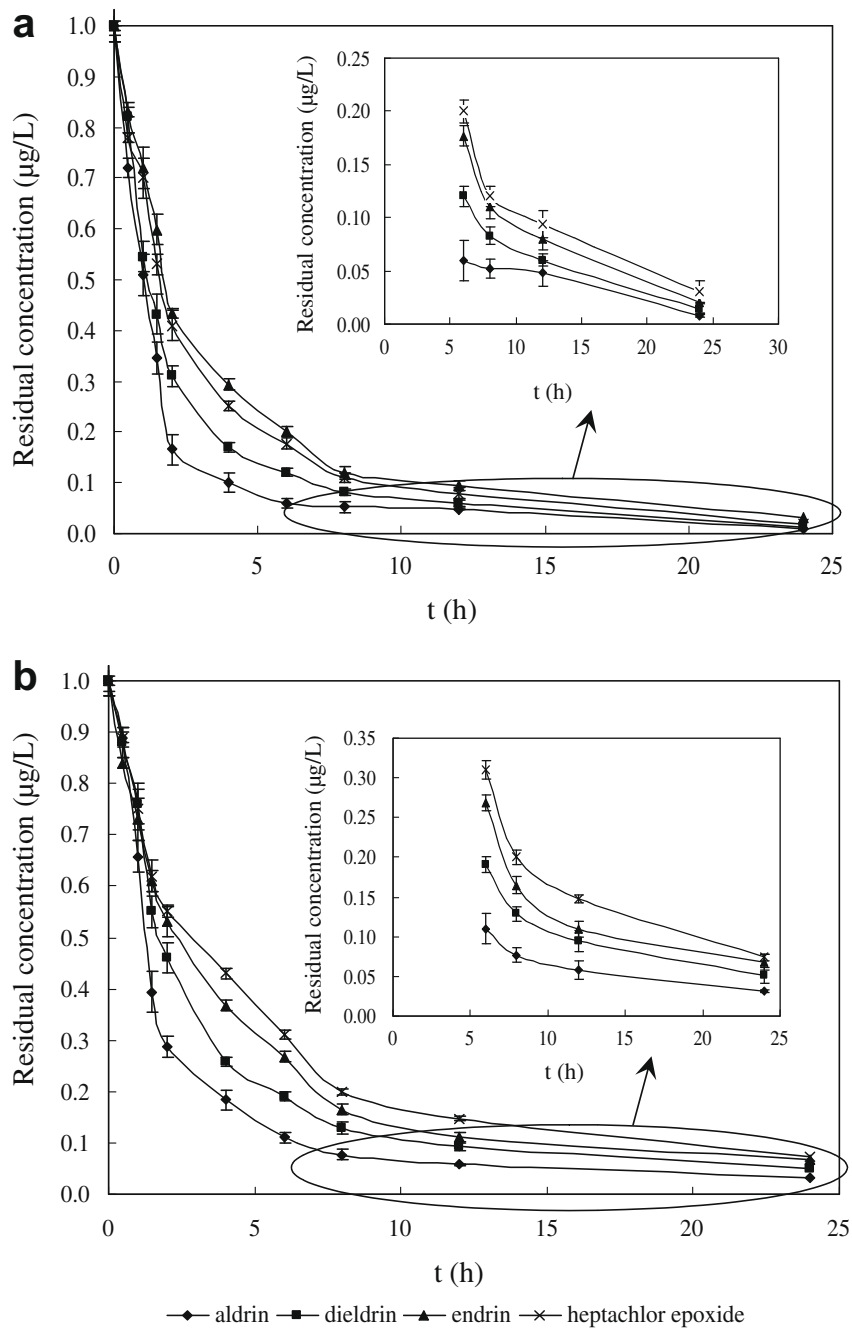

Fig. 2. Residual concentration of four selected POPs as a function of time (a) CAtriolein absorbent (b) CA absorbent (mixed POPs solution, initial concentration of each POP: $1 \mu \mathrm{g} / \mathrm{L}$; liquid: $200 \mathrm{~mL}$; absorbent: $1 \mathrm{~g}$. Error bars represent standard deviation).
$0.03 \mu \mathrm{g} / \mathrm{L}$, respectively. CA absorbent had the same trends as CAtriolein absorbent for four POPs except higher residual concentrations of $0.03,0.05,0.07$ and $0.07 \mu \mathrm{g} / \mathrm{L}$, respectively.

Experimental results were fitted by the pseudo-second-order kinetic model, which can be solved with the following equations. The kinetic rate equation is expressed as:

$d q_{t} / d t=k_{2}\left(q_{\mathrm{eq}}-q_{t}\right)^{2}$,

where $q_{\mathrm{eq}}$ is the equilibrium sorption capacity and $q_{t}$ is the solidphase loading of POPs at time $t . k_{2}\left(\mu \mathrm{g} \mathrm{g}^{-1} \mathrm{~h}^{-1}\right)$ represents the pseudo-second-order rate constant (Guo and Chen, 2005). By integrating Eq. (1) with the boundary conditions of $q_{t}=0$ at $t=0$ and $q_{t}=q_{t}$ at $t=t$, the following linear equations can be obtained:

$\frac{t}{q_{t}}=\frac{1}{V_{0}}+\frac{1}{q_{\mathrm{eq}}} t$

and

$V_{0}=k_{2} q_{\mathrm{eq}}^{2}$,

where $V_{0}\left(\mu \mathrm{g} \mathrm{g}^{-1} \mathrm{~h}^{-1}\right)$ is the initial sorption rate. The $V_{0}$ and $q_{\mathrm{eq}}$ values can be determined experimentally by plotting $t / q_{t}$ versus $t$.

Table 3 shows parameters in the pseudo-second-order kinetic model estimated for each compound by means of linear fitting. The pseudo-second-order model fits the kinetic data of CA and CA-triolein absorbents very well, indicating very high determination coefficients of above 0.98 . The values of the initial absorption rates of POPs on CA-triolein ranged between 0.09 and $0.25 \mu \mathrm{g} \mathrm{g}^{-1} \mathrm{~h}^{-1}$, which increased with increasing hydrophobicity of POPs, and indicated the excellent selectivity of triolein to hydrophobic POPs. Table 3 also shows that the initial absorption rates of POPs on CA-triolein were higher than that of CA. This result confirmed that the removal of hydrophobic compounds by the CA-triolein absorbent may be attributed to both absorption to CA and uptake by triolein.

\subsection{Absorption isotherms of the selected POPs}

Linear equilibrium uptake isotherm (Eq. (4)) was used to correlate the equilibrium data.

$C_{\mathrm{m}}=K C_{\mathrm{w}}$

where $C_{\mathrm{m}}$ represents the mass of compound accumulated per unit of absorbent, ng/g. $C_{\mathrm{w}}$ represents the equilibrium concentration of the absorbate, $\mu \mathrm{g} / \mathrm{L}$ and $K$ is the absorbent-water distribution coefficient.

Fig. 3 shows the absorption isotherms of the four organic compounds by CA-triolein and CA absorbents at $\mathrm{pH} 6.8$ and $25^{\circ} \mathrm{C}$. For CA and CA-triolein absorbent, the selected POPs exhibited linear equilibrium uptake isotherms. Table 1 summarizes the absorption data for the four POPs on CA-triolein and CA absorbent along with the related physical properties. High correlation coefficients ( $>0.97$ ) suggested that a linear equilibrium model was suitable for describing the absorption equilibrium. The linear equilibrium uptake isotherms indicated that the POPs were mainly absorbed onto CA-triolein absorbent by a partition mechanism. Partitioning

Table 3

Parameters of a pseudo-second-order kinetic model fitting the absorption kinetics of the four POPs.

\begin{tabular}{|c|c|c|c|c|c|c|}
\hline \multirow[t]{2}{*}{ Compound } & \multicolumn{3}{|c|}{ CA-triolein absorbent } & \multicolumn{3}{|l|}{ CA absorbent } \\
\hline & $V_{0}\left(\mu g^{-1} h^{-1}\right)$ & $k\left(\mathrm{~g} \mu \mathrm{g}^{-1} \mathrm{~h}^{-1}\right)$ & $r^{2}$ & $V_{0}\left(\mu g g^{-1} h^{-1}\right)$ & $k\left(\mathrm{~g}_{\mu} \mathrm{g}^{-1} \mathrm{~h}^{-1}\right)$ & $r^{2}$ \\
\hline Aldrin & 0.25 & 5.78 & 0.998 & 0.12 & 2.62 & 0.980 \\
\hline Deldrin & 0.15 & 3.47 & 0.992 & 0.09 & 1.89 & 0.988 \\
\hline Endrin & 0.11 & 2.51 & 0.998 & 0.08 & 1.89 & 0.998 \\
\hline Heptachlor epoxide & 0.09 & 2.05 & 0.997 & 0.07 & 1.48 & 0.999 \\
\hline
\end{tabular}



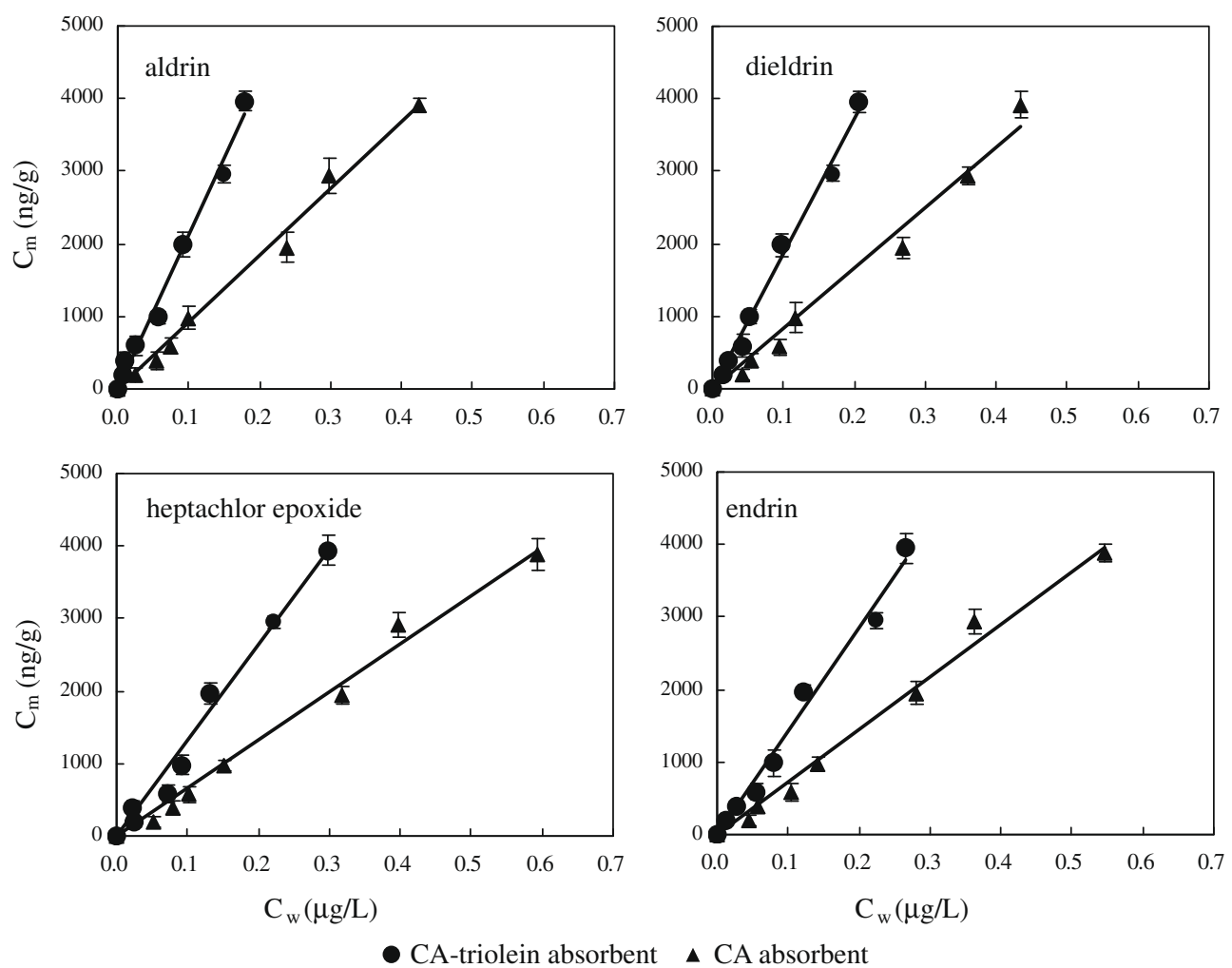

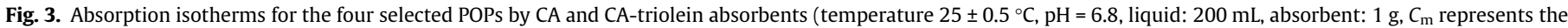

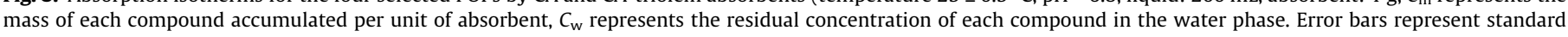
deviation).

of organic solutes between water and triolein may be treated in a manner similar to that between an organic solvent phase and water.

The finding that absorption of POPs from water on CA-triolein absorbent is mainly a partition process was further tested by comparing the single-solute and binary-solute isotherms of dieldrin and endrin. The results in Fig. 4 show no apparent competitive effect, further confirming the partitioning mechanism. Generally,

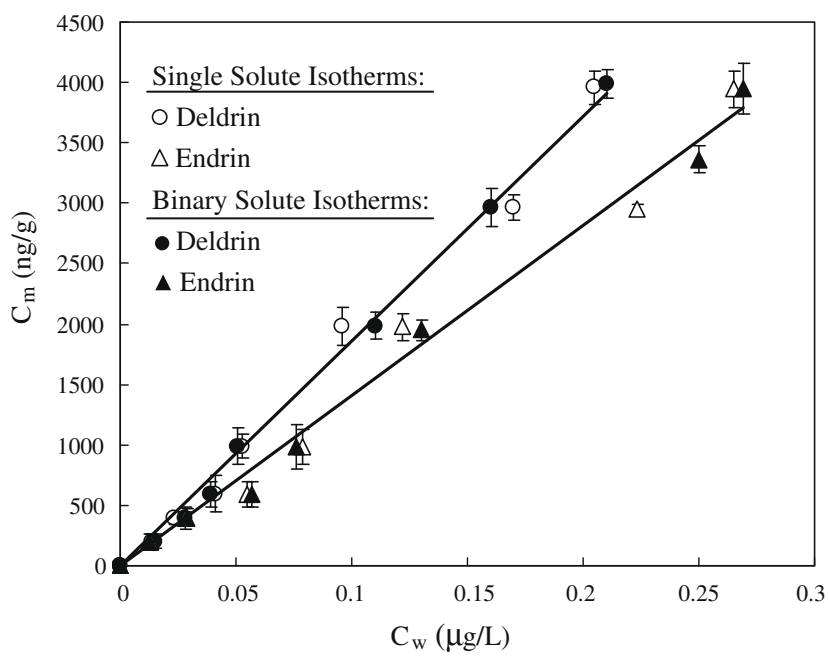

Fig. 4. Absorption isotherms for dieldrin and endrin in single solute and in binary solutes on CA-triolein absorbent. (Temperature $25 \pm 0.5^{\circ} \mathrm{C}, \mathrm{pH}=6.8$, liquid: $200 \mathrm{~mL}$, absorbent: $1 \mathrm{~g}, C_{\mathrm{m}}$ represents the mass of each compound accumulated per unit of absorbent, $C_{\mathrm{w}}$ represents the residual concentration of each compound in the water phase. Error bars represent standard deviation.) competition would indicate adsorption, and independent absorption indicates partitioning (Chiou et al., 1983).

The absorption constant, $K$, is related to the $\log K_{\text {ow }}$ of the POPs. For example, strongly hydrophobic compounds such as aldrin and dieldrin had higher $K$ values than endrin or heptachlor epoxide. In addition, the $K$ value of CA-triolein sorbent was higher than that of CA sorbent for the same compound. This suggested that strongly hydrophobic compounds with high $\log K_{\text {ow }}$ values had a much greater tendency to accumulate in the triolein phase than in the CA phase, which was similar to the results of Xu et al. (2005).

\subsection{Thermodynamic analysis of POPs absorption on CA-triolein absorbent}

A thermodynamic analysis was conducted of the absorption of the four POPs on CA-triolein absorbent at different temperatures. Thermodynamic parameters, such as the change in free energy $\left(\Delta G^{0}\right)$, enthalpy $\left(\Delta H^{0}\right)$ and entropy $\left(\Delta S^{0}\right)$, were calculated from the variation of the thermodynamic equilibrium constant $K_{0}$ with the change in temperature. The calculation methods employed are discussed in detail by Niwas et al. (2000). The value of $K_{0}$ for the adsorption reaction can be defined as follows:

$K_{0}=\frac{\alpha_{s}}{\alpha_{e}}=\frac{v_{s}}{v_{e}} \cdot \frac{C_{s}}{C_{e}}$

where $\alpha_{s}$ is the activity of the adsorbed solute, $\alpha_{e}$ is the activity of the solute in solution at equilibrium, $C_{\mathrm{s}}$ is the surface concentration of organic pollutants in millimoles per gram of CA-triolein absorbent, $C_{\mathrm{e}}$ is the concentration of organic pollutants at equilibrium $\left(\mathrm{mmol} \mathrm{ml} \mathrm{l}^{-1}\right), v_{s}$ is the activity coefficient of the adsorbed solute and $v_{e}$ is the activity coefficient of the solute in solution. As the concentration of the solute in the solution approaches zero, the activity coefficient approaches unity, reducing Eq. (5) to the following form: 
$K_{0}=\frac{\alpha_{s}}{\alpha_{e}}=\frac{C_{s}}{C_{e}}$

The values of $K_{0}$ are obtained by plotting $\ln \left(C_{\mathrm{s}} / C_{\mathrm{e}}\right)$ versus $C_{\mathrm{s}}$ and extrapolating $C_{\mathrm{s}}$ to zero. The straight line obtained is fitted to the points based on a least-squares analysis. Its intercept with the vertical axis gives the values of $K_{0}$. Standard free energy changes $\left(\Delta G^{0}\right.$, $\mathrm{kJ} \mathrm{mol}^{-1}$ ) for interactions are calculated from the relationship:

$\Delta G^{0}=-R T \ln K_{0}$

where $R$ is the universal gas constant, $8.314 \mathrm{~J} \mathrm{~mol}^{-1} \mathrm{~K}^{-1}$, and $T$ is the temperature in Kelvin. The average standard enthalpy change $\left(\Delta H^{0}\right.$, $\mathrm{kJ} \mathrm{mol}^{-1}$ ) is then calculated from the Van't Hoff equation:

$\ln K_{0}\left(T_{3}\right)-\ln K_{0}\left(T_{1}\right)=\frac{-\Delta H^{0}\left(T_{1} \text { to } T_{3}\right)}{R}\left(\frac{1}{T_{3}}-\frac{1}{T_{1}}\right)$

where $T_{3}$ and $T_{1}$ are two different temperatures.

Standard entropy changes $\left(\Delta S^{0}, \mathrm{~kJ} \mathrm{~mol}^{-1} \mathrm{~K}^{-1}\right)$ are calculated using the equation

$\Delta G^{0}=\Delta H^{0}-T \Delta S^{0}$

The values obtained are given in Table 4 . A positive value of the standard enthalpy change $\left(\Delta H^{0}\right)$ indicated that the absorption of four POPs on CA-triolein absorbent were endothermic. This was supported by the increasing absorption of four POPs with the increase in temperature. All $\Delta H^{0}$ values were lower than $30 \mathrm{~kJ} \mathrm{~mol}^{-1}$, indicating that the absorption of POPs on the CA-triolein was a physical process. In the absorption process, the $\Delta H^{0}$ values of aldrin and dieldrin were lower than those of endrin and heptachlor epoxide, suggesting that the absorption is more favorable for the hydrophobic organic chemicals. Since the free energy changes $\left(\Delta G^{0}\right)$ were negative and were accompanied by positive entropy changes $\left(\Delta S^{0}\right)$, the reactions were spontaneous, with high affinity for the absorption of the POPs on CA-triolein absorbent. The negative $\Delta G^{0}$ value increased with an increase in temperature, indicating that the spontaneous nature of absorption is proportional to the temperature.

\subsection{Reusability of CA-triolein absorbent}

The treatment cost is a major concern in large-scale plants and the reusability of the CA-triolein absorbent became important. In the present study, hexane was used to extract the POPs from CAtriolein absorbent. Previous study had proved that CA and CA-triolein absorbents were stable in hexane, with negligible weight loss of triolein and CA dialysis (Xu et al., 2005). The reusability of the CA-triolein absorbent was examined by the batch experiment for five cycles and the results were shown in Fig. 5. Although the CA-triolein absorbent was regenerated five times, the removal effi-

Table 4

Thermodynamic parameters of POPs absorption on CA-triolein.

\begin{tabular}{lllll}
\hline Compound & $T$ & $\begin{array}{l}\Delta G^{0} \\
(K)\end{array}$ & $\begin{array}{l}\Delta H^{0} \\
\left(\mathrm{~kJ} \mathrm{~mol}^{-1}\right)\end{array}$ & $\begin{array}{l}\Delta S^{0} \\
\left(\mathrm{~kJ} \mathrm{~mol}^{-1} \mathrm{~K}^{-1}\right)\end{array}$ \\
\hline Aldrin & 283.15 & -20.76 & 13.64 & 0.30 \\
& 298.15 & -27.73 & & 0.31 \\
Dieldrin & 313.15 & -29.70 & & 0.30 \\
& 283.15 & -19.62 & 19.67 & 0.33 \\
Endrin & 298.15 & -27.05 & & 0.33 \\
& 313.15 & -29.40 & & 0.33 \\
Heptachlor epoxide & 283.15 & -19.56 & 22.83 & 0.25 \\
& 298.15 & -24.80 & & 0.26 \\
& 293.15 & -27.19 & & 0.25 \\
& 298.15 & -18.49 & 26.05 & 0.26 \\
& 313.15 & -26.34 & & 0.27 \\
\hline
\end{tabular}

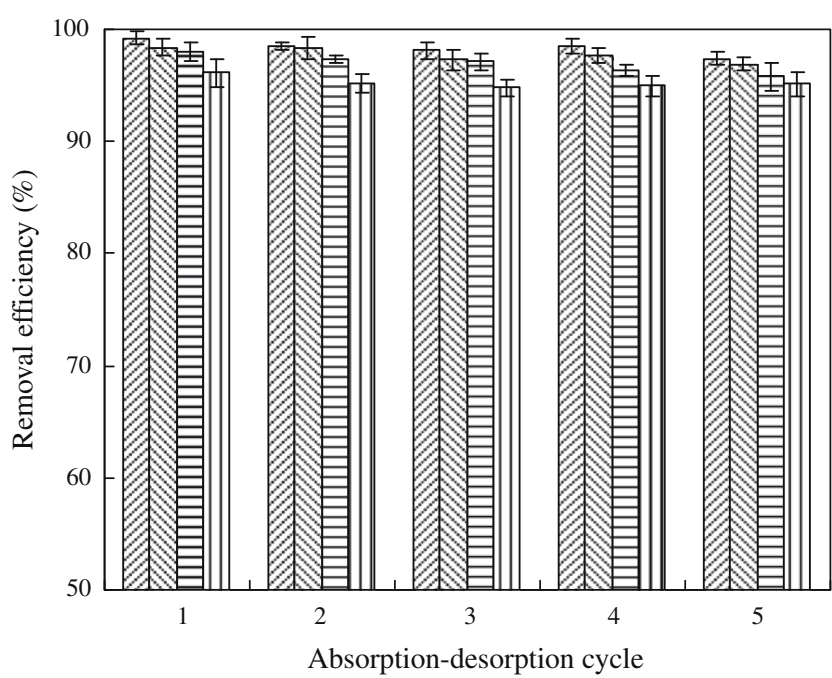

— Aldrin $\mathrm{Q}$ Deldrin $\boxminus$ Endrin $\square$ Heptachlor epoxide

Fig. 5. Absorption-desorption cycle of CA-triolein absorbent. (Error bars represent standard deviation.)

ciencies for four POPs were maintained at more than $96 \%$ and no decreasing trend appeared. Through analyzing the POPs concentration in hexane, nearly all of the POPs were detected in the organic solvent phase indicating that almost all the CA-triolein absorbent had been well recovered. The reusability of the CA-triolein beads after the extraction of hexane would be interpreted as due to an equilibrium reaction between CA and triolein and the POPs, which involves the intercalation-deintercalation process of a CA and CAtriolein absorbent. When the CA heads were immersed in a hexane environment, molecules of the POPs could be removed to the organic phase and the equilibrium reaction would be inclined to deintercalation accordingly.

\subsection{Fixed-bed column runs}

The practical way to design an absorption column is to conduct experiments with a mini-column. In the fixed-bed column experiment, take mixed POPs solution as influent and the concentrations of each POPs ranging from 1 to $1.5 \mu \mathrm{g} / \mathrm{L}$. The POPs were percolated through CA and CA-triolein absorbent columns. The choice of this range of concentration was based on what was reported in the literature (Zhang et al., 2002; Kang et al., 2003), where the expected levels in surface water do not normally exceed $1.5 \mu \mathrm{g} / \mathrm{L}$.

EBCT is a critical parameter when absorption experiments are involved because the removal efficiency depends strongly on the contact time between the absorbent and absorbate. The removal efficiency of POPs was investigated at EBCTs of 3, 5, and $20 \mathrm{~min}$. As expected, EBCT evidently affected the absorption, and the absorption efficiency increased with increasing EBCT, due to the resulting higher contact time. Preliminary experiments showed that at EBCT of $20 \mathrm{~min}$, the selected POPs remaining in solution was continuously below $0.1 \mu \mathrm{g} / \mathrm{L}$ (USEPA, 2002), so 20 min was chosen as the EBCT for a long run. Fig. 6 shows breakthrough behavior during fixed-bed column runs at EBCT of $20 \mathrm{~min}$.

The initial column experiment indicated that CA-triolein absorbent had high removal efficiency for four POPs. When the influent concentration was $1-1.5 \mu \mathrm{g} / \mathrm{L}$ and the EBCT was $20 \mathrm{~min}$, the breakthrough empty-bed volumes (BV) of aldrin, dieldrin, endrin and heptachlor epoxide at the value of $0.1 \mu \mathrm{g} / \mathrm{L}$ on CA absorbent was $1800,1400,1200$ and 900, respectively. While for the CA-triolein absorbent, performed until $3200 \mathrm{BV}$, did not reach the breakthrough point. 

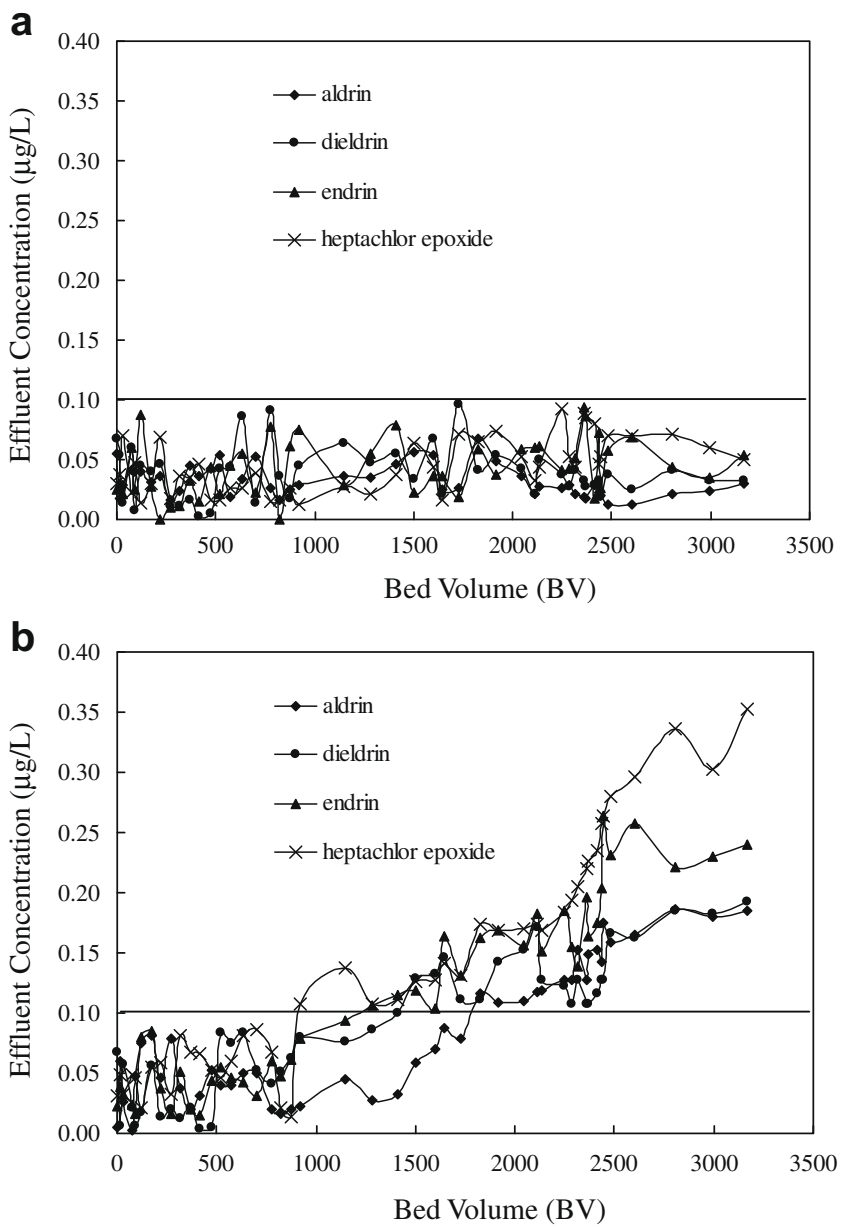

Fig. 6. Breakthrough behavior of the column test (a) CA-triolein absorbent; (b) CA absorbent (influent: mixed POPs solution, concentration of each compound: 1$1.5 \mu \mathrm{g} / \mathrm{L}$, EBCT: $20 \mathrm{~min})$.

Above results showed that CA-triolein absorbent can efficiently remove hydrophobic POPs from water at low concentration. CAtriolein absorbent is cost effective and has the following features: the raw material and chemical agents used for the preparation of CA-triolein absorbent are common and cheap and the preparation procedures for CA-triolein are simple. The absorbent was prepared with pollution-free and environmentally friendly raw materials and the spherical absorbent is compatible with fixed-bed column processes with excellent mechanical strength and attrition resistance properties. CA-triolein absorbent does not change water quality. In conclusion, there are good prospects for CA-triolein absorbent in practical applications for the removal of hydrophobic contaminated from drinking water.

\section{Conclusions}

A triolein embedded CA spherical absorbent was developed, which was found to be effective for the removal of hydrophobic POPs from aqueous solution, especially at low concentrations. The adsorption isotherm data of the four selected POPs showed that a partition mechanism existed between the POPs and the CA-triolein absorbent. The absorption constant was proportional to the $\log K_{\text {ow }}$ of the compound. Kinetic data fitted well to the pseudo-second-order reaction model. The initial sorption rate was dependent on both the initial concentration and the $\log K_{\text {ow }}$ of the absorbates. Absorption rate was favored at high initial concen- trations and high $\log K_{\mathrm{ow}}$ of the absorbate. In addition, there was no apparent competitive effect on the binary pollutants removal by CA-triolein absorbent. Thermodynamic analysis of POPs absorption on CA-triolein absorbent showed that the absorption was spontaneous, with a high affinity and the absorption was an endothermic reaction. Hexane extraction was a good regeneration method for CA-triolein absorbent reuse. Adsorption properties of the CA-triolein absorbent remain stable after 5 adsorption/desorption cycles. Initial column experiments indicated that CA-triolein absorbent has practical application potential for the removal of hydrophobic contaminated from drinking water.

\section{Acknowledgements}

The authors appreciate the generous financial support of this work from the National Natural Science Foundation of China (50578154).

\section{References}

Ahmed, E.N., Aly, M.A.A., 2004. Organochlorine contamination in some marketable fish in Egypt. Chemosphere 54, 1401-1406.

Andersen, G., Kovacs, K.M., Lydersen, C., Skaare, J.U., Gjertz, I., Jenssen, B.M., 2001. Concentrations and patterns of organochlorine contaminants in white whales (Delphinapterus leucas) from Svalbard, Norway. Sci. Total Environ. 264, 267-281.

Azza, K., Ahmed, E.N., Tarek, O.S., Amany, E.S., Aly, M.A.A., 2004. Polychlorinated biphenyls and chlorinated pesticides in mussels from the Egyptian Red Sea coast. Chemosphere 54, 1407-1412.

Bembnowska, A., Pelech, R., Milchert, E., 2003. Absorption from aqueous solutions of chlorinated organic compounds onto activated carbon. J. Colloid Interf. Sci. 265, 276-282.

BrÁs, I.P., Santos, L., Alves, A., 1999. Organochlorine pesticide removal by pinus bark sorption. Environ. Sci. Technol. 33, 631-634.

Chiou, C.T., Porter, P.E., Schmedding, D.W., 1983. Partition equilibrium of nonionic organic compounds between soil organic matter and water. Environ. Sci. Technol. 17, 227-231.

Crisafully, R., Milhome, M.A.L., Cavalcante, R.M., Silveira, E.R., Keukeleire, D.D., Nascimento, R.F., 2008. Removal of some polycyclic aromatic hydrocarbons from petrochemical wastewater using low-cost adsorbents of natural origin. Bioresour. Technol. 99, 4515-4519.

Ferreira, M., Antunes, P., Costa, J., Amado, J., Gil, O., Pousão-Ferreira, P., Vale, C., ReisHenriques, M.A., 2008. Organochlorine bioaccumulation and biomarkers levels in culture and wild white seabream (Diplodus sargus). Chemosphere 73, 16691674.

Frank, S.L., 2005. Review of passive accumulation devices for monitoring organic micropollutants in the aquatic environment. Environ. Pollut. 136, 503-524.

Guo, J.J., Liu, L.H., Liu, X.R., Lu, J., Zhou, H.D., Huang, S.B., Wang, Z.J., Spear, P.A., 2008. Occurrence and distribution of organochlorine pesticides-lindane, p, ṕ-DDT, and heptachlor epoxide-in surface water of China. Environ. Int. 34, 1097-1103.

Guo, X.J., Chen, F.H., 2005. Removal of arsenic by bead cellulose loaded with iron oxyhydroxide from groundwater. Environ. Sci. Technol. 39, 6808-6818.

Huckins, J.N., Tubergen, M.W., Manuweera, G.K., 1990. Semipermeable membrane devices containing model lipid: a new approach to monitoring the bioavailability of lipophilic contaminants and estimating their bioconcentration potential. Chemosphere 20, 533-552.

Kang, Y.H., Liu, P.B., Wang, Z.J., Lv, Y.B., Li, Q.J., 2003. Persistent organochlorinated pesticides in water from the Guanting reservoir and the Yongding river, Beijing. J. Lake Sci. 15, 125-132.

Ke, R.H., Xu, Y.P., Wang, Z.J., Khan, S.U., 2006. Estimation of the uptake rate constants for polycyclic aromatic hydrocarbons accumulated by semipermeable membrane devices and triolein-embedded cellulose acetate membranes. Environ. Sci. Technol. 40, 3906-3911.

Lee, S.Y., Kim, S.J., Chung, S.Y., Jeong, C.H., 2004. Sorption of hydrophobic organic compounds onto organoclays. Chemosphere 55, 781-785.

Li, J.M., Meng, X.G., Hu, C.W., Du, J., 2009. Adsorption of phenol, p-chlorophenol and p-nitrophenol onto functional chitosan. Bioresour. Technol. 100, 1168-1173.

Liu, H.J., Qu, J.H., Dai, R.H., Ru, J., Wang, Z.J., 2007. A biomimic adsorbent for removal of trace level persistent organic pollutants from water. Environ. Pollut. 147, 337-342.

Liu, X.D., Murayama, Y., Matsunaga, M., Nomizu, M., Nishi, N., 2005. Preparation and characterization of DNA hydrogel bead as selective adsorbent of dioxins. Int. J. Biol. Macromol. 35, 193-199.

Mackay, D., 1982. Correlation of bioconcentration factors. Environ. Sci. Technol. 16, 274-278.

Matsui, Y., Fukuda, Y., Inoue, T., Matsushita, T., 2003. Effect of natural organic matter on powdered activated carbon adsorption of trace contaminants: characteristics and mechanism of competitive adsorption. Water Res. 37, 4413-4424. 
Niwas, R., Gupta, U., Khan, A.A., Varshney, K.G., 2000. The adsorption of phosphamidon on the surface of styrene supported zirconium (IV) tungstophosphate: a thermodynamic study. Colloid Surface A 164, 115-119.

USEPA., 822-R-02-038, 2002. Edition of the Drinking Water Standards and Health Advisories. Office of Water US Environmental Protection Agency, Washington, DC.

Wang, Z.S., Liu, W.J., 2001. Drinking water treatments for micropollutant water resources, First ed. China Architecture and Building Press, Beijing.
Xu, Y.P., Wang, Z.J., Ke, R.H., Khan, S.U., 2005. Accumulation of organochlorine pesticides from water using triolein embedded cellulose acetate membranes. Environ. Sci. Technol. 39, 1152-1157.

Zhang, Z.L., Hong, H.S., Wang, X.H., Lin, J.Q., Chen, W.Q., Xu, L., 2002. Determination and load of organophosphorus and organochlorine pesticides at water from Jiulong river estuary. China Mar. Pollut. Bull. 45, 397-402. 